REVIEW

\title{
What Happened -The Outline of the Fukushima Accident
}

\author{
Mamoru BABA* \\ Cyclotron and Radioisotope Center, Tohoku University \\ Aramaki, Aza-Aoba, Sendai 980-8578, Japan
}

\begin{abstract}
The outline of the accident of the Fukushima-Daiichi Nuclear Power Plant is described on the basis of public information until August 10,2011. The accident was triggered by a massive earthquake and a successive tsunami as high as $14 \mathrm{~m}$ at the site, and resulted in meltdown of three reactor cores in Units 1, 2,3 and hydrogen explosion in three reactor buildings in Units 1,3,4, although other ten units hit by the tsunami could reach cold shutdown. A large amount of radioactive materials, $\sim 15 \%$ of that in the Chernobyl accident, was discharged, and the evacuation was required for residents even in regions beyond $30 \mathrm{~km}$ where dose rate would exceed $20 \mathrm{mSv} / \mathrm{yr}$.
\end{abstract}

\section{KEYWORDS: accident, outline, nuclear power plant, Fukushima-Daiichi, earthquake, tsunami}

\section{Introduction}

At 2;46 p.m., on March 11, 2011, a massive earthquake with a magnitude of 9.0 occurred off the coast of Miyagi prefecture in east Japan facing the Pacific Ocean. The earthquake was followed by a huge tsunami whose height was around $14 \mathrm{~m}$ at the site. The earthquake and tsunami hit fourteen nuclear power plants (NPPs) existing along the coast and caused serious damage to four reactor units at the Fukushima Daiichi (I) NPP of Tokyo Electric Power Co. Ltd. (TEPCO).

The accident was caused by the loss of core cooling because the offsite power was lost by the earthquake, and emergency diesel generators and seawater pumps were disabled by the tsunami. The accident resulted in melt down of three reactor cores and thereby discharges of a large amount of radioactive materials, leading to evacuation of residents living near the NPP.

This report briefly describes the outline of the accident on the basis of information from published papers ${ }^{1-4)}$, and official information from the Japanese Government ${ }^{5-8}$ ) including NISA ${ }^{6}$ (Nuclear and Industry Safety Agency) of the Ministry of Economy, Trade and Industry, monitoring data on radiation dose ${ }^{7)}$ and foods contamination ${ }^{8)}$, and technical information from TEPCO ${ }^{9}$. However, note that the report is still preliminary and may contain incorrectness.

\section{Outline of the Accident \\ 1. Nuclear Power Plants ${ }^{1,2,49}$}

In Japan, 54 NPPs were providing totally $48 \mathrm{GW}$, about 30 $\%$ of the electricity. Among them, fourteen NPPs shown in Figure 1 were hit by the earthquake and tsunami on March 11, 2011: Onagawa NPP of Tohoku Electric Power Co. (3 units), Fukushima-I (6 units), and Fukushima-II (4 units) of TEPCO,

* Corresponding Author, E-mail: babam@cyric.tohoku.ac.jp

(C) 2012 Atomic Energy Society of Japan, All Rights and Tokai-II (1 unit) of Japan Atomic Power Company. Among them, at the time of earthquake, Units 4-6 in Fukushima-I, and Tokai-II were stopped for periodical inspection. Fuels in reactors and spent fuels in the pool should be cooled continuously even after operation to avoid overheating due to decay heat.

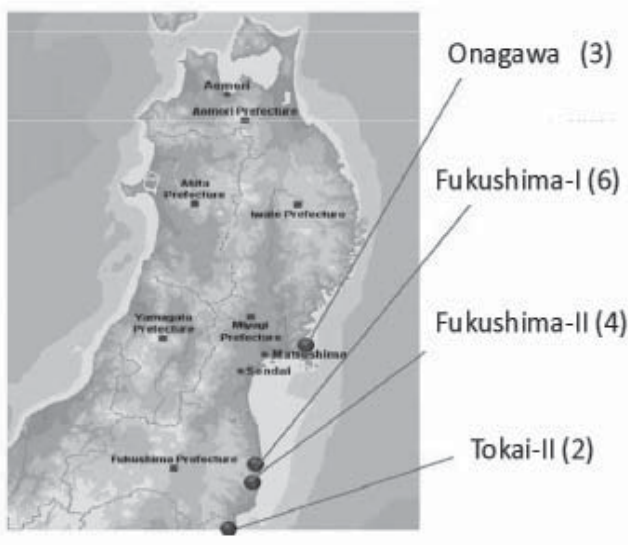

Fig. 1 Nuclear power plants in east Japan hit by the earthquake and tsunami on March 11,2011,6. The number in parenthesis indicates the number of units.

The reactors in these fourteen NPPs were BWRs (Boiling Water Reactors) with a structure shown in Figure 2. The pressure vessel for reactors is housed inside a Containment Vessel (CV), and further with a reactor building. It should be noted that in BWR, a pool for spent fuel cooling exists in the top floor of the reactor building. In BWRs, a turbine generator is driven by a primary steam from the reactor itself, while PWRs (Pressurized Power Reactors) use secondary steam generated in the heat exchanger.

Fortunately, nine NPPs other than the Units 1-4 in Fukushima I NPP could be stopped and cooled down safely owing to the availability of emergency power source and/or offsite power and heat sinks as described later ${ }^{1-6)}$. 


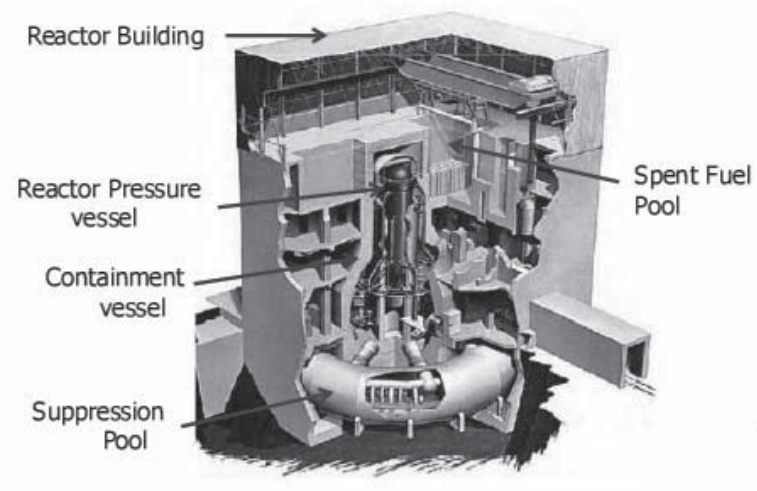

Fig. 2 Schematics of BWRs in Fukushima No.1 NPPs ${ }^{1,3)}$.

\section{Process of the Accident ${ }^{1-6,9)}$}

In Figure 3, the plan view of the Fukushima No.1 NPP after the accident is shown. The reactor buildings of Units 1, 3 and 4 in the left side are seriously damaged. The layout of Units 1 through 4 is very similar, and oil tanks for emergency diesel generator (EDG) and seawater pumps were placed in the sea side without covering buildings.

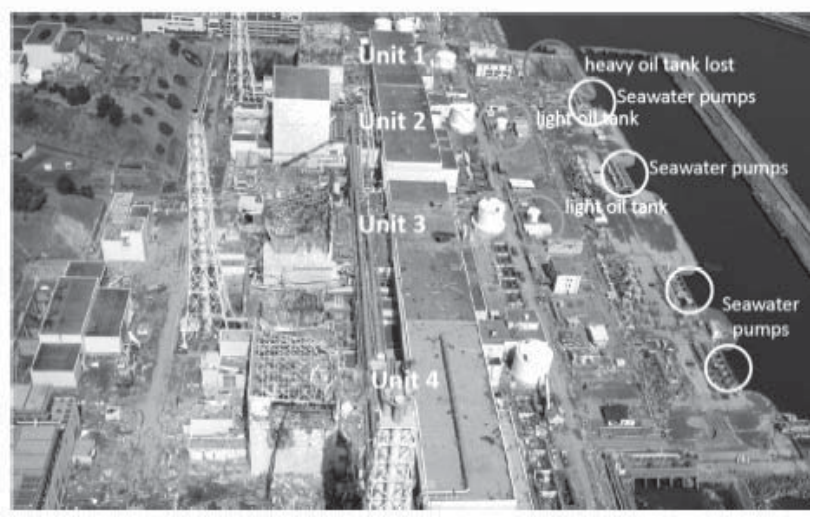

Fig. 3 Plan view of Fukushima No.1 NPP after accident ${ }^{1,9)}$ :

At 2:46 p. m., March 11, the earthquake $(M=9.0)$ occurred. The maximum acceleration by the earthquake in FukushimaI NPP was ab out 550 gal in east-west direction ${ }^{1,5,6,9)}$ which was about 1.2 times as large as the design base. The reactors and turb ines of Un its 1,2 and 3 stop ped au tomatically. However, transmission line towers and other equipments on the plant grounds collapsed as a result of the earthquake and it disabled the Units 1 through 6 from receiving external AC power. EDG s tarted up aut omatically, and further Isolated Condenser (IC) in the Unit 1 and a steam-driven Reactor Core Isolation Cooling (RCIC) sy stem in Uni ts 2 an d 3 driven by battery st arted o peration for $\mathrm{c}$ ore $\mathrm{c}$ ooling automatically or manually. It is reported, however, that IC in Unit 1 was st opped $m$ anually about ei ght minutes 1 ater ${ }^{4)}$ because it might cause too rapid temperature change.

About an hour later, at 3:41 p.m., however, the major tsunami hit the Fukushima-I NPP. The tsunami was as high as $\sim 14 \mathrm{~m}$ at the site and higher than that occurred in east Japan in 869. The tsunami was higher than assumed in design. As shown in Figure 4, therefore, the tsunami flooded the EDGs in turbine buildings which were not water-tight.
The seawater pumps were providing the heat sinks for core cooling. In this situation, all AC power was lost and operation continued on battery power alone, and active core cooling was not possible. There was no power in the control room as well, making all operations and monitoring of the plant difficult. TEPCO reported the situation to the national and local governments according to the Nuclear Disaster Special Measures Law. As the water injection volume into the emergency core cooling system could not be measured, TEPCO judged that all cooling functions had been lost, and at 4:36 p.m. reported the occurrence of a nuclear emergency situation to the national and local governments. In response, the government announced a nuclear emergency situation at 7:03 p. m. on March 11.

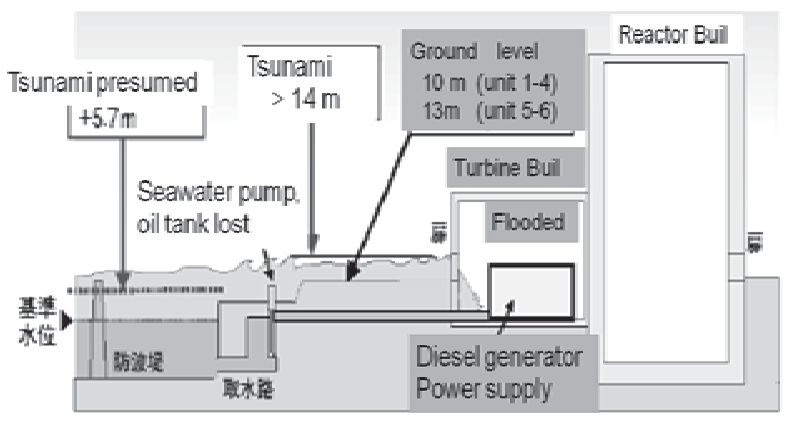

Fig. 4 Schematic view of tsunami and the equipment ${ }^{1,4,9)}$.

Meanwhile, the loss of cooling function continued too at the spent fuel pools in Units 1 through 4.

As a result of the situation, the decay heat could not be removed from the core to the seawater. As the batteries had also been exhausted, adequate cooling was not possible and the water level lowered than the top of fuel rods. The temperature of the fuel rods rose rapidly, and the zirconium in the fuel cladding tubes reacted with the water vapor and produced large quantities of hydrogen. Consequently, early in the morning on March 12, the pressure in the containment vessel of Unit 1 began to rise due to the leakage from the reactor pressure vessel.

Accordingly the reactor vessel was vented at 2:30 p.m. to release the gas. However, at 3:36 p.m., a hydrogen explosion occurred inside the reactor building blowing the building apart. In order to make cooling of core, the fire service system was used to pump in seawater at 8:20 p. m.

At Unit 3, cooling was conducted using the RCIC system, and at 1:00 p. m. on March 12 cooling using a high-pressure coolant injection system started because the water level became low. However, at 2:42 a.m. on March 13, the high-pressure coolant injection system stopped operating, and it became impossible to start up the RCIC as well. The pressure in the reactor vessel rose sharply, and at 8:41 a.m. the reactor vessel was vented, and seawater was pumped in at 1:12 p.m. At 11:01 a. m. on March 14, however, a hydrogen explosion occurred inside the Unit 3 reactor building and destroyed the building.

At Unit 2, the RCIC system was functioning but not stable, then the reactor core was not cooled appropriately. At 11:30 a.m. on March 14, the RCIC system stopped functioning. 
Although workers began pumping in seawater at 4:34 p.m., the fuel was above water level for an extended period of time. Venting was initiated at 12:02 a.m. on March 15, and at 6:10 a.m. an abnormal noise was heard near the pressure suppression chamber and the pressure dropped. It is presumed that there was a full-fledged release of the radioactive materials inside the containment vessel. This was subsequently confirmed by measurements of radiation in the atmosphere that were made public.

At Unit 4, the reactor core was empty and all the fuel rods were in the spent fuel pool. However, a hydrogen explosion occurred at 6:14 a.m. on March 15, destroying the building as well. The hydrogen explosion proved to be due to hydrogen which was produced in Unit 3 core and leaked to the Unit 4 building through a conduit connecting the buildings of Units 3 and 4. Therefore, the damage of the spent fuels in the pool was not serious.

\section{Emergency Cooling and Power Restoration ${ }^{1-6,9)}$}

Restoration of external electricity was an urgent task to enable stationary water pumping into the core and the spent fuel pool. On March 21 and 22, external power was restored partially for lightening and extended to powers for pumping.

In Units 1 through 4, cooling of the reactor cores and the fuel rods at the spent fuel pools had to be continued against decay heat. However, as the cooling water circulating pumps were no longer functioning, the temperature of the water in the spent fuel pools in Units 3 and 4 rose and the water level dropped. On March 17, the spent fuel pools in Units 3 and 4 were sprayed with sea waters by the Tokyo Fire Department, Self Defense Force etc. Subsequently, the discharge of water, etc. using concrete pumping vehicles continued, and the work crews gradually shifted from the use of seawater to the use of freshwater to avoid erosion and deterioration of heat conduction.

The discharge and pumping of water into the reactor cores and spent fuel pools, led to the situation that water containing large quantities of radioactive materials flowed out into the ground below the turbine buildings and other areas. The highly radioactive water in the turbine building must be removed and the cooling system should be changed to circulation cooling. On April 2, it was discovered that highly radioactive water was flowing into the ocean from a crack in the outlet at Unit 2. In order to stop the leak of highly radioactive water and transfer it to the centralized waste treatment facility, on April 4 the low-concentration contaminated water that had been in the centralized waste treatment facility was discharged into the ocean. Besides, since April 6, nitrogen was pumped into the containment vessel of Unit 1 to prevent hydrogen explosion and extended to the Units 2 and 3 successively.

\section{Difference between Fukushima-I NPP and others ${ }^{1,4-6,9)}$}

It will be worthwhile to see what difference was there between Units 1 through 4 in Fukushima-I NPP and others which reached cold shutdown safely.

The Units 5 and 6 in Fukushima-I NPP were also hit by the tsunami. However, one EDG in Unit 6 continued to function because it was air-cooled one and stored in a water-tight building not flooded by the tsunami. As a result of this cooling operation, Units 5 and 6 achieved cold shutdown on March 20.

Similarly, in Fukushima-II NPP, the electric equipments were protected from the tsunami because they were enclosed in a water-tight building.

In Onagawa NPP, the ground level of the site was $14.8 \mathrm{~m}$ and higher than the tsunami, $\sim 13 \mathrm{~m}$, and consequently the NPP could reach to cold shutdown with the help of emergency cooling system. The situation was similar in Tokai-II NPP, and it reached cold shutdown safely.

\section{Evacuation of Residents around Fukushima-I NPP ${ }^{1,2)}$}

On the evening of March 11, the evacuation of residents from areas within 3 kilometers of the plant was ordered by the Prime Minister because of the concern regarding the possible leakage of radiation from the Fukushima-I NPP. Residents living in the area of 3 to $10 \mathrm{~km}$ around the NPP were also ordered to stay indoor. On the following day, March 12, the radiation dose in the area around the plant increased, and the evacuation zone was expanded to $10 \mathrm{~km}$ around the plant, and shortly thereafter extended to $20 \mathrm{~km}$. On March 15, residents living in the area 20 to $30 \mathrm{~km}$ around the plant were instructed to stay indoors. Approximately 140,000 people live within a $30 \mathrm{~km}$ radius of the plant, and of these approximately 87,000 people live within $20 \mathrm{~km}$ of the plant.

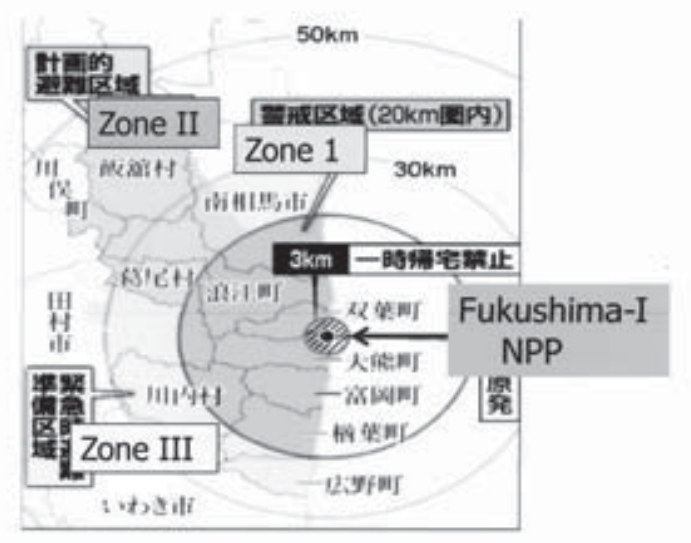

Fig. 5 Emergency planning zone for the accident ${ }^{1,2)}$.

On April 10, on the basis of radiation dose rate measured in air at various locations and calculation made using the SPEEDI system (System for Prediction of Environmental Emergency Dose Information), NSC indicated that there were areas northwest of the NPP in which the integrated dose rate would exceed $20 \mathrm{mSv}$ per year, and presented measures to deal with the situation to the government. Based on the recommendations of NSC, on April 22, the government declared the area $20 \mathrm{~km}$ around the Fukushima-I NPP Zone I an "Evacuation (Caution) Zone" to which entry was prohibited (Figure 5). In addition, the instruction to remain indoors was lifted for the area 20 to $30 \mathrm{~km}$ around the NPP and the area northwest from the Caution Zone outside $20 \mathrm{~km}$ of the plant was designated a Zone II "Planned Evacuation Zone" and required to evacuate within around one month. Also, Zone III, "Emergency Evacuation Preparation Zones" were assigned to the areas within the zone 20 to $30 \mathrm{~km}$ around 
Evacuation measures were needed to protect the health of residents by avoiding physical radiation effect (deterministic effect). However, many of the residents who evacuated with bare hands have to continue to live under difficult conditions. For the reason, one occasion is being provided for them to back to their homes under controlled conditions.

The official announcement of the SPEEDI results was too late and it made difficult to do evacuation promptly to minimize the unwanted exposure of residents.

\section{Radioactivity Release Re-6) $^{2,5}$}

Assessment of the radioactivity release to atmosphere by the accident has been reported from NISA and NSC. It was carried out on the basis of inventory of nuclides and the analysis using severe accident analysis codes.

NISA $^{6)}$ presented revised estimation on June 6 and reported that the emission of radioactivity was $1.6 \times 10^{17}$ (Chernobyl case: $\left.1.8 \times 10^{18}\right) \mathrm{Bq}$ for ${ }^{131} \mathrm{I}$ and $1.5 \times 10^{16}(8.5 \times$ $\left.10^{16}\right) \mathrm{Bq}$ for ${ }^{137} \mathrm{Cs}$. The fraction of emitted activities is estimated to be about 0.4 to $7 \%$ for Units 1 through 3 . The total value given in iodine equivalent unit is $7.7 \times 10^{17}(5.2 \times$ $\left.10^{18}\right) \mathrm{Bq}$. The estimated value of radioactivity emission is about $15 \%$ of the Chernobyl case, but it corresponds to level 7 in INES (International Nuclear and Radiological Event Scale) of IAEA as well as that in the Chernobyl case.

A significant amount of radioactivity was emitted also to the ocean because of leakage of highly contaminated water from the reactor cores and of emission of low level contaminated water in the storage tank to prepare a storage space for highly contaminated water. They are estimated to be $4.7 \times 10^{15} \mathrm{~Bq}$ and $1.5 \times 10^{11} \mathrm{~Bq}$, respectively, which requires long term monitoring of marine contamination.

Major emission of radioactivity occurred between March 11 and March 21. Since then, the concentration of radioactivity in air decreased steadily and became lower than a detection limit in the middle of April, although the radioactivity proved to be transported beyond $100 \mathrm{~km}$ as shown by the contamination of rice straw and grasses in Miyagi prefecture, green tea in Shizuoka prefecture etc. The monitoring of ground was performed systematically and trials for decontamination of soil and living spaces are started in various area.

\section{Recovery Actions ${ }^{1,2,9)}$}

In this stage, the reactor cores and spent fuel pools were cooled by injection or spray of water, because the original cooling system was not usable at all. Then water injected or sprayed accumulated in the reactor and turbine buildings as highly radioactive one by the radioactivity from the melted fuels. Therefore, to avoid the danger that the contaminated water flowed out of the site, it was urgently required to construct a system of circulation cooling. Besides, the plant should be made safe against further earthquake (aftershock), tsunami, and various natural disasters. Therefore the following actions were undertaken: recovery and duplication of external power supply, construction of a circulation cooling system equipped with decontamination and purification system, complement of structural integrity of reactor buildings and spent fuel pools, preparation of building covers, nitrogen injection into Containment Vessel to prevent hydrogen explosion, elimination of radioactive debris and fixing of radioactivity etc, as well as extension of radiation monitoring.

At the end of July, a circulating cooling system was completed. It started operation and enabled cooling of three reactor cores and four spent fuel pools without increasing the inventory of highly contaminated water in the site. Circulation cooling for reactor cores and spent fuel pools was achieved by use of air-cooled heat exchangers, and the system is equipped with absorbers of cesium and other radio nuclides as well as desalination provisions.

Until the beginning of August, the reactors and spent fuel pools have not reached to cold shutdown completely but are becoming much more stable, and the risk of further emission of radioactivity seems very low. Efforts are continued for cold shutdown of reactors and pools, and for minimizing residual risks.

\section{Summary}

An overview was given on the severe accident in Fukushima -I nuclear power plant. Three reactors, Units 1-3, in the plant were seriously damaged and melted down because of the loss of both external and emergency AC powers and heat sinks caused by a massive earthquake and tsunami. It resulted in discharge of large amount of radioactivity, about $15 \%$ of the Chernobyl accident, over a wide area. It will be important to take actions and promote research for recovery of environment from the contamination by radioactive materials.

The details of the accident should be traced further to clarify what were the problems. It should be noted that other nine plants were also hit by the disaster but could reach to cold shutdown successfully. It will be important to learn lessons from this fact what is important in sever accident of power reactors.

\section{References}

1) Akira Omoto, "Fukushima Accident: An overview" http://www.sfen.org/IMG/pdf/icapp2011_Omoto.pdf -

2) Report to the Foreign Academie s from Scientif ic Council of Japan on the Fukushima Daiichi Nuclear Power Plant Accident, May 2, 2011, http://www.scj.go.jp/en/index.html

3) Yoshiaki Oka, TEPCO's Nuclear Power Plant suffered from big earthquake of March 11, 2011, http://smc-japan.sakura.ne.jp/wordpress/wp.

4) S. Suzuki: BWR Reacto rs, http://wwwsoc.nii.ac.jp/jrsm/jrsm, (in Japanese)

5) Report of Japanese Government to the IAEA Ministerial Conference on Nuclear Safety- The Accident at TEPCO's Fukushima Nuclear Power Stations -

http://www.kantei.go.jp/foreign/kan/topics/201106/iaea_houko kusho_e.html

6) http://www.nisa.meti.go.jp/english/index.html

7) http://radioactivity.mext.go.jp/en/

8) http://www.mhlw.go.jp/english/topics/2011eq/index.html

9) http://www.tepco.co.jp/en/nu/fukushima-np/index-e.html 